\title{
Hepatocyte growth factor can guide treatment of Mycoplasma pneumoniae pneumonia in children
}

\author{
LUN QIN LIU $^{1 *}$, ZHI HUA WANG ${ }^{2 *}$ and HAI YUN YAO ${ }^{3}$ \\ ${ }^{1}$ Department of Inspection, Infectious Diseases Hospital of Jinan, Jinan, Shandong 250021; ${ }^{2}$ Department of Pediatrics, \\ Tianjin Nankai Hospital, Tianjin Medical University, Tianjin 300100; ${ }^{3}$ Department of Inspection, \\ Jinan Blood Center, Jinan, Shandong 250001, P.R. China
}

Received January 8, 2019; Accepted February 2, 2020

DOI: $10.3892 /$ etm.2020.8596

\begin{abstract}
The objective of the present study was to explore the role of hepatocyte growth factor (HGF) in directing treatment of Mycoplasma pneumoniae pneumonia (MP). Serum levels of HGF were assessed using ELISA in 65 pediatric patients with MP, 42 with bacterial pneumonia and 30 healthy controls. Serum levels of C-reactive protein (CRP), the standard guide for MP treatment, were also examined in severe and non-severe MP. The sensitivity and specificity of HGF and CRP in assessing the outcome of azithromycin treatment of MP were compared using receiver operating characteristic curves. HGF levels were elevated in MP and bacterial pneumonia patients compared with healthy controls. HGF levels were also significantly higher in severe MP than in non-severe MP. HGF showed higher sensitivity and specificity than CRP in assessing outcomes of azithromycin treatment of MP. The results of the present study indicated that HGF may be used to detect severe MP and to direct its management. Furthermore, HGF may be better predictive marker to assess the effectiveness of azithromycin treatment of MP than CRP.
\end{abstract}

\section{Introduction}

Hepatocyte growth factor (HGF) was originally discovered as a mitogen of hepatocytes in adult rats and exhibits a cytotoxic effect in certain tumor cells, such as those in hematoma (1-2). HGF is a paracrine factor that is secreted by mesenchymal cells, such as fibroblasts, bronchial epithelial cells, alveolar macrophages and neutrophils, and plays an important role in

Correspondence to: Dr Hai Yun Yao, Department of Inspection, Jinan Blood Center, 127 Jingliu Road, Jinan, Shandong 250001, P.R. China

E-mail: yhy504@126.com

*Contributed equally

Key words: hepatocyte growth factor, Mycoplasma pneumoniae, pediatric pneumonia, $\mathrm{C}$-reactive protein lung development, inflammation and tissue repair (3-5). The biological effect of HGF is mediated by the cell membrane receptor MET (6). HGF synthesis is regulated by prostaglandins, cytokines and hormones, while its cellular secretion is stimulated by acute phase proteins, such as tumor necrosis factor- $\alpha$ (TNF- $\alpha)$, interleukin (IL)-1 $\alpha$, IL-1 $\beta$, IL-6, platelet derived growth factor and fibroblast growth factor $\beta$, as well as cyclic adenosine monophosphate (7-10). HGF can be detected in edema fluid during acute lung injury, where it is produced locally by fibroblasts and inflammatory cells (11-14). HGF is therefore used to assess progression of Legionella pneumonia (15), solitary pulmonary nodules (16) and bacterial pneumonia (17).

Mycoplasma pneumoniae pneumonia (MP), which is unresponsive to commonly used antibiotics such as penicillin, is caused by a microorganism associated with atypical pneumonia (18). Mycoplasma pneumoniae infections vary dramatically in clinical presentation, ranging from mild and self-limiting upper respiratory symptoms to radiographically confirmed pneumonia that requires hospitalization (19). In some cases, Mycoplasma pneumoniae infection may result in severe clinical consequences that involve organs other than lungs, such as encephalitis and acute hepatitis, which is known as extrapulmonary complications $(20,21)$. As the Mycoplasma pneumoniae incubation period can last as long as 3 weeks, and prolonged shedding follows infection, outbreaks often go unnoticed and the course of infection can extend for long periods of time (22). The clinical detection of Mycoplasma pneumoniae relies on serological IgM testing or PCR assay; culture is rarely used because the microorganism grows very slowly $(23,24)$. Macrolides are the treatment of choice for MP, while tetracyclines and fluoroquinolones also prove to be effective (25).

Pneumonia treatment is particularly important in children, as it remains the most common cause of mortality and morbidity in children $<5$ years of age globally (26). Although preventable, pneumonia can lead to chronic lung conditions, such as pulmonary fibrosis, if it is recurrent or untreated (27). A study among a Finnish population reported that MP was detected in $30 \%$ of pediatric community-acquired pneumonia patients and in $>50 \%$ children aged 5 years or older (28).

In the present study, serum HGF levels were assessed in $\mathrm{MP}$ as well as in bacterial pneumonia. 


\section{Materials and methods}

Patient enrollment. Children ( $\mathrm{n}=137$; age range, 3-14 years; mean age, $6.7 \pm 3.5$ ) who visited the Pediatric Department of Tianjin Nankai Hospital between January 2014 and June 2015 were enrolled in the study, including 65 cases of MP, 42 cases of bacterial pneumonia and 30 healthy children who visited the department for health examinations. This study was approved by The Ethics Committee of Tianjin Nankai Hospital (approval no. 2017-018P), which waived written consent, because the study was observational and residual blood after completing the routine follow-up was used. Oral consent for participation in the study was obtained from each patient and their parent.

Diagnosis of MP and bacterial pneumonia. The inclusion criteria were a combination of: i) Fever; ii) cough; iii) breathing crackles; iv) lung consolidation, and v) serum IgM against Mycoplasma pneumoniae $\geq 1: 160$ at the first day of admission or an increase in IgG against Mycoplasma pneumoniae at least 4 times by the 7th day following admission (29). Patients were also not responsive to penicillin, cephalosporins or sulfonamide.

Severe MP $(\mathrm{n}=27)$ was defined as in the guidelines of community-acquired pneumonia management in children in China (30). It was diagnosed if a patient met at least two of criteria i-iii or either of criteria iv and v. The criteria were: i) Obvious tachycardia or tachypnea (respiratory rate $\geq 40$ breaths per minute or heart rate $\geq 140$ beats per minutes in children aged $1-5$ years; respiratory rate $\geq 30$ breaths per minute or heart rate $\geq 120$ beats per minutes in children aged over 5 years); ii) unresponsive to $\beta$-Lactam antibiotics; iii) lung consolidation that involved more than one lobe of the lung confirmed by chest x-ray; iv) complicated with pleural effusion or pulmonary necrosis/abscess, and v) partial pressure of oxygen less than $60 \mathrm{mmHg}(7.98 \mathrm{Ka})$ or involvement of other organs.

Cases of bacterial pneumonia were diagnosed by blood culture and culture of the expectorated sputa with no contamination, as indicated by scanty squamous epithelium but dominant with columnar epithelium (31).

Exclusion criteria. The exclusion criteria were any of the following: i) Patients were infected by another pathogen within 7 days of hospital stay; ii) patients were in the recovery stage of pneumonia since their admission, as shown by stable body temperature and resolved chest $\mathrm{x}$-ray; iii) patients with a past history of bronchial asthma or recurrent pulmonary infection; iv) primary or secondary immune-compromised patients; v) patients with complicated renal, pulmonary, liver, cardiovascular or connective tissue diseases, and vi) patients with incomplete medical history.

Determination of $H G F, W B C, L D H$, alanine aminotransferase (ALT), aspartate aminotransferase (AST) and CRP levels. Serum levels of HGF in each sample were determined by ELISA (cat. no. E01H0208; Blue Gene) according to the manufacturer's instructions while WBC, LDH, ALT, AST and CRP levels were assessed using ADVIA 2400 Clinical Chemistry System (Siemens Healthineers). HGF and CRP lebels were examined on the day of admission and at 2 days after admission.
Azithromycin administration. All patients who suffered from MP were administered azithromycin (10 mg/kg/day) intravenously on the day of admission for 2 days. Readings were then taken on the third day to confirm whether patients have responded to treatment. Patients were evaluated and further divided into two groups according to the effectiveness of azithromycin. Treatment was determined to be effective if systemic symptoms such as fever, myalgia and headache were resolved and respiratory symptoms improved. This was based on the recommendations of the guidelines of community-acquired pneumonia management in children in China (30).

Statistical analysis. All statistical analyses were performed using SPSS v17.0 (SPSS, Inc.). Continuous variables are presented as the mean \pm standard deviation (SD) or median values with interquartile range (IQR). Normally distributed parameters between multiple groups were tested using one-way ANOVA followed by Tukey's multiple comparison test. Normally distributed parameters between two groups were examined with unpaired t-tests. The Mann-Whitney U test was used to compare serum CRP levels, which were not normally distributed. Discrete variables between multiple groups were analyzed using the $\chi^{2}$ test. Receiver operating characteristic (ROC) curve analysis was used to analyze the discriminative power of laboratory markers to predict the efficacy of macrolides in MP. $\mathrm{P}<0.05$ was considered to indicate a statistically significant difference.

\section{Results}

There were no significant differences between age and sex of the subjects in the control, bacterial pneumonia and MP groups. Additionally, there were no significant differences between ALT and AST levels among the three groups (Table I). CRP levels significantly differed among bacterial pneumonia, MP pneumonia and control subjects $(\mathrm{P}<0.001$; Table I). As indicated in Fig. 1A, serum HGF levels were significantly higher in the MP and bacterial pneumonia groups compared to levels in control subjects on the day of admission before treatment $(\mathrm{P}<0.05)$. HGF levels did not vary significantly between MP and bacterial pneumonia (Fig. 1A). Similarly, CRP levels did not vary significantly between MP and bacterial pneumonia (Fig. 1B), while LDH levels are significantly higher in MP pneumonia compared with bacterial pneumonia $(\mathrm{P}<0.05$; Fig. $1 \mathrm{C})$. Patients who suffered from MP were divided into severe MP $(n=27)$ and non-severe MP ( $n=38)$, according to the guidelines of community-acquired pneumonia management in children in China (30). HGF was significantly higher in severe MP than in non-severe MP on the day of admission $(\mathrm{P}<0.05$; Fig. 2A). In addition, CRP was significantly higher in severe MP [17.8 (5.5-30.1) $\mathrm{mg} / \mathrm{l}]$ than in non-severe MP [5.9 (2.4-25.0) mg/l; Table II; Fig. 2B] as was LDH (337.0 \pm 120.3 vs. $256.9 \pm 54.4 \mathrm{IU} / 1$; Table II; Fig. $2 \mathrm{C}$ ). There were no obvious differences in sex, WBC count and liver function (as indicated by ALT and AST) between severe cases and non-severe cases. However, the average age of severe MP patients was significantly older than that of non-severe patients (Table II). 
Table I. Clinical characteristics of patients in all three groups.

Patient group

\begin{tabular}{lcccr}
\cline { 2 - 3 } Variables & MP & Bacterial pneumonia & Healthy control & P-value \\
\hline No. of cases & 65 & 42 & 30 & \\
Mean age (years) & $7.2 \pm 3.2$ & $5.8 \pm 3.7$ & $6.9 \pm 3.4$ & 0.089 \\
Sex (male/female) & $36 / 29$ & $18 / 24$ & $14 / 16$ & 0.406 \\
WBC count (x/ $\mu$ l) & $8,585.2 \pm 3,985.9$ & $9,992.4 \pm 4,819.2$ & $6,283.3 \pm 1,394.8$ & 0.001 \\
LDH (IU/l) & $290.2 \pm 95.7$ & $259.0 \pm 59.1$ & $130.1 \pm 29.5$ & $<0.001$ \\
ALT (IU/l) & $18.5 \pm 6.7$ & $18.1 \pm 6.5$ & $20.3 \pm 5.6$ & 0.349 \\
AST (IU/l) & $28.0 \pm 9.3$ & $30.1 \pm 8.1$ & $27.2 \pm 5.2$ & 0.275 \\
CRP $(\mathrm{mg} / \mathrm{l})$ & $9.5(3.6-28.0)$ & $20.1(5.2-36.3)$ & $<0.8$ & $<0.001$
\end{tabular}

CRP data is presented as median with interquartile range, while other parameters were shown as mean. \pm standard deviation. MP, Mycoplasma pneumoniae pneumonia; LDH, lactate dehydrogenase; ALT: alanine aminotransferase; AST, aspartate aminotransferase; WBC, white blood cell; CRP, C-reactive protein.
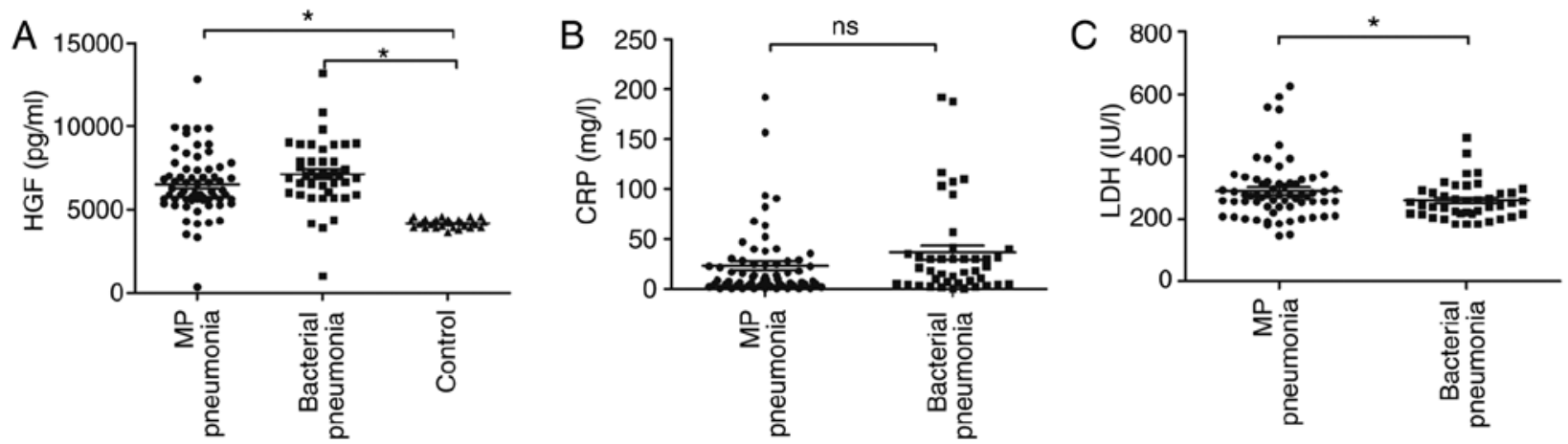

Figure 1. Serum HGF levels in MP ( $n=65)$, bacterial pneumonia $(n=42)$ and healthy control patients $(n=30)$ on the day of admission. (A) HGF levels were significantly higher in both MP and bacterial pneumonia compared when with control subjects. (B) CRP levels did not differ significantly between MP and bacterial pneumonia patients. (C) LDH levels were significantly lower in bacterial pneumonia patients than MP patients. Data are presented as the mean \pm SD. ${ }^{*} \mathrm{P}<0.05$ vs. healthy control patients; CRP, C-reactive protein; HGF, hepatocyte growth factor; LDH, lactate dehydrogenase; MP; Mycoplasma pneumoniae pneumonia; ns, not significant.
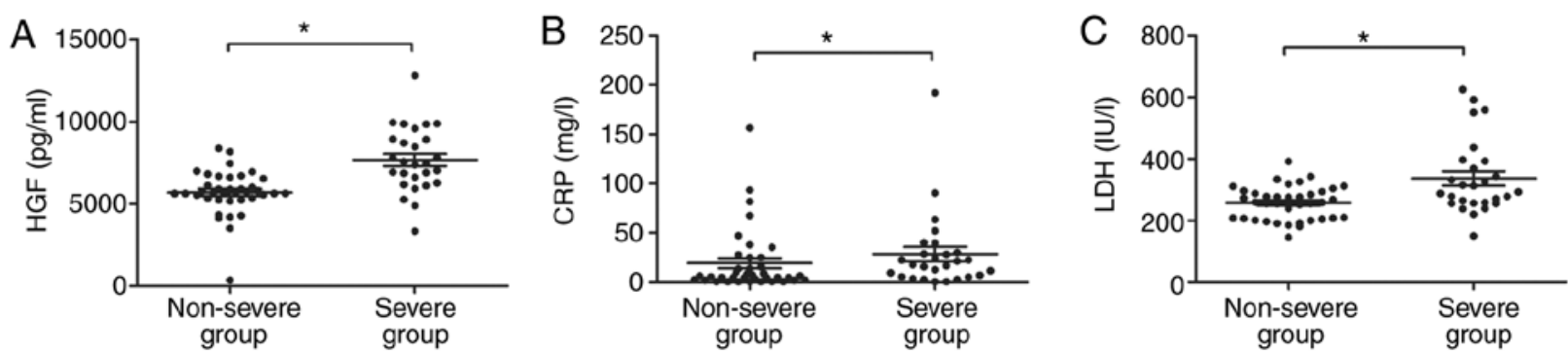

Figure 2. Serum HGF, CRP and LDH levels in patients with severe MP and non-severe MP at the first day of admission. (A) HGF, (B) CRP and (C) CRP were significantly higher in severe MP $(n=27)$ compared with non-severe MP $(n=38)$. Data are presented as the mean \pm SD. ${ }^{*} P<0.05$. CRP, C-reactive protein; HGF, hepatocyte growth factor; LDH, lactate dehydrogenase; MP; Mycoplasma pneumoniae pneumonia.

In those 42 patients who responded to 2 days of azithromycin treatment, serum HGF levels dropped significantly ( $\mathrm{P}<0.05$; Fig. 3A) as did CRP levels ( $\mathrm{P}<0.05$; Fig. 3B). In addition, $\mathrm{LDH}$ was also significantly reduced $(\mathrm{P}<0.05$; Fig. $3 \mathrm{C})$. There was no evident change in HGF, CRP or LDH $(\mathrm{P}>0.05)$ in the 23 patients who were not responsive to azithromycin treatment (Fig. 3).
Finally, the sensitivity and specificity of CRP, LDH and HGF in assessing effectiveness of azithromycin treatment were compared. As indicated in Fig. 4, HGF showed advantage over CRP and LDH in evaluating azithromycin treatment with higher sensitivity or specificity $(\mathrm{P}<0.05)$. The sensitivity (97.6\%) and specificity (78.3\%) levels of HGF were both higher than those of CRP (91.2\% sensitivity; $69.1 \%$ for 
Table II. Comparison of clinical characteristics of patients with differing severities of MP.

\begin{tabular}{lccr}
\hline & \multicolumn{2}{c}{ MP severity } & P-value \\
\cline { 2 - 4 } Variables & Non-severe & Severe & 0.004 \\
\hline No. of cases & 38 & 27 & 0.324 \\
Mean age (years) & $6.3 \pm 3.1$ & $8.5 \pm 3.1$ & 0.291 \\
Sex (male/female) & $19 / 19$ & $17 / 10$ & 0.003 \\
WBC count (x/ $\mu$ l) & $9,028.2 \pm 4,258.9$ & $7,961.9 \pm 3,550.1$ & 0.201 \\
LDH (IU/l) & $256.9 \pm 54.4$ & $337.0 \pm 120.3$ & 0.768 \\
ALT (IU/l) & $17.5 \pm 4.1$ & $19.9 \pm 9.2$ & 0.038 \\
AST (IU/l) & $27.8 \pm 9.0$ & $28.4 \pm 9.8$ & $17.8(5.5-30.1)$ \\
CRP (mg/l) & $5.9(2.4-25.0)$ &
\end{tabular}

ALT, alanine aminotransferase; AST, aspartate aminotransferase; CRP, C-reactive protein; LDH, lactate dehydrogenase; MP, Mycoplasma pneumoniae pneumonia; WBC, white blood cell. CRP is presented as median with interquartile range while other parameters were shown as mean with standard deviation.
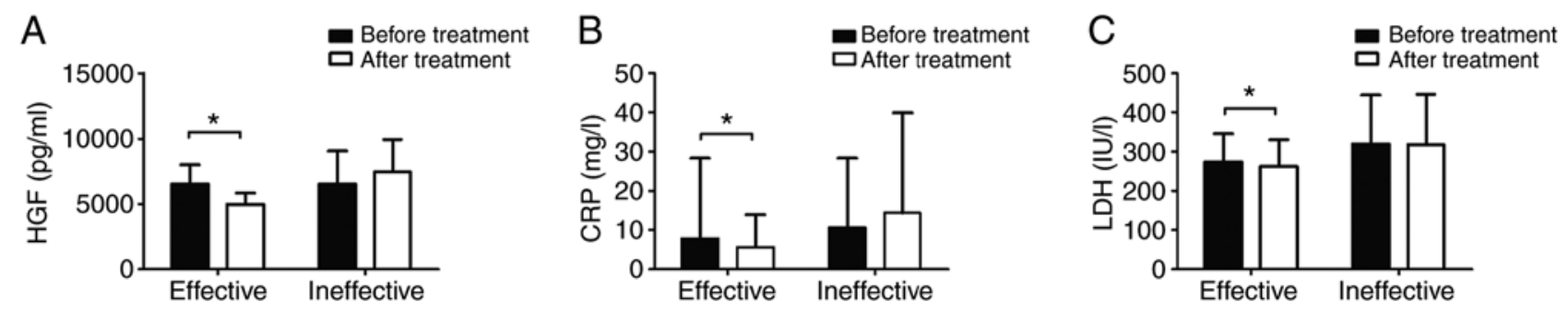

Figure 3. Serum HGF, CRP and LDH levels in patients with MP after $48 \mathrm{~h}$ azithromycin treatment. (A) HGF, (B) CRP and (C) LDH levels fell in subjects who were response to treatment $(\mathrm{n}=42)$ but did not change in subjects for whom the treatments were ineffective $(\mathrm{n}=23)$. Data are presented as the mean $\pm \mathrm{SD}$. ${ }^{*} \mathrm{P}<0.05$. CRP, C-reactive protein; HGF, hepatocyte growth factor; LDH, lactate dehydrogenase; MP; Mycoplasma pneumoniae pneumonia.

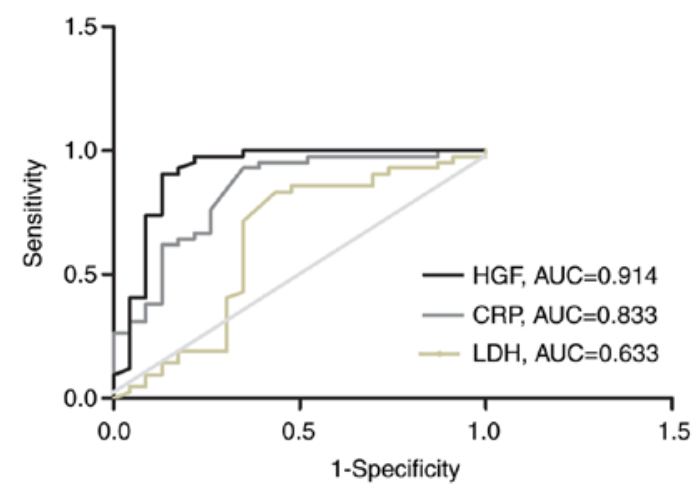

Figure 4. ROC curves. ROC curves showed the sensitivity and specificity of CRP, $\mathrm{LDH}$ and HGF in predicting effectiveness of azithromycin treatment for $48 \mathrm{~h}$ in $65 \mathrm{MP}$ patients. HGF exhibited a significant advantage in assessing azithromycin over CRP and LDH. The optimal cutoff value of HGF was $8,468 \mathrm{pg} / \mathrm{ml}$, with a sensitivity of $97.6 \%$ and a specificity of $78.3 \%$. CRP, C-reactive protein; HGF, hepatocyte growth factor; LDH, lactate dehydrogenase; MP; Mycoplasma pneumoniae pneumonia; ROC, receiver operating characteristic.

specificity) and LDH (85.1\% sensitivity; 70.2\% specificity), respectively (Table III).

\section{Discussion}

HGF is known to be elevated in Legionella pneumonia (15) and bacterial pneumonia (17), which led to the hypothesis that it may be elevated in MP. When children are infected with Mycoplasma pneumoniae IL-2, IL-6 and TNF- $\alpha$ are released into the peripheral blood (32), which can stimulate secretion of HGF (10). HGF is also known to be secreted at high levels in viral pneumonia and HGF/MET signaling enhances the innate immune response, by stimulating the secretion of IL-8 and granulocyte macrophage colony-stimulating factor (33). Additionally, both HGF and CRP levels correlated with the severity of MP, as shown in the present study. HGF has been used to assess the severity of avian origin influenza A (H7N9) virus and worked as an independent outcome predictor (34). Therefore, HGF has been suggested to act as a general indicator of activity of the innate immune response, rather than as a specific marker for MP. However, this does not impede its application in assessing MP. Interestingly, the present study showed that LDH was also upregulated in severe MP. In the present study LDH was used as a biomarker to predict refractory MP, which is characterized by prolonged fever and hospital stay as well as more severe pulmonary symptoms in children (35) as an alternative to erythrocyte sedimentation rate and CRP (36). LDH may be an indicator of severity of MP. In the present study, the mean age of severe MP patients was higher than non-severe ones, which may be due to the more mature immune system in older children causing longer duration of fever, higher CRP, and more severe pulmonary lesions compared to younger patients. 
Table III. A comparison of sensitivity and specificity of LDH, CRP and HGF.

\begin{tabular}{lccc}
\hline Parameter & $\begin{array}{c}\text { Sensitivity } \\
(\%)\end{array}$ & $\begin{array}{c}\text { Specificity } \\
(\%)\end{array}$ & $95 \%$ CI \\
\hline HGF & 97.6 & 78.3 & $0.817-1.000$ \\
CRP & 91.2 & 69.1 & $0.725-0.942$ \\
LDH & 85.1 & 70.2 & $0.473-0.792$ \\
\hline
\end{tabular}

CRP, C-reactive protein; HGF, hepatocyte growth factor; $\mathrm{LDH}$, lactate dehydrogenase; CI, confidence interval.

Determining the severity of pneumonia is not always straightforward. The World Health Organization criteria divide the severity of pneumonia into 2 grades: Severe pneumonia and very severe pneumonia (37). Although there is an association between these classifications and clinical outcome $(38,39)$, it is still a relatively coarse classification system and does not consider population variation due to geography. As all subjects in the present study were Chinese children, Chinese national guidance was applied to divide pediatric pneumonia into severe and non-severe cases (30). Identifying severe cases of MP is important, because the use of steroids is advocated alongside antibiotics for such cases (30). Macrolides have been shown to be effective in severe cases of Mycoplasma pneumoniae infection (25). The results of the present study suggest that HGF levels could be assessed to determine whether children with MP require early steroid treatment.

$\beta$-lactam antibiotics, including penicillin and cephalosporins, are considered to be the drugs of choice for treating respiratory diseases, as they are active against most respiratory bacterial pathogens (40). However, they are ineffective against Mycoplasma pneumoniae because they target the cell wall, while Mycoplasma pneumoniae lacks a cell wall (41). Macrolides and tetracyclines, which act as protein synthesis inhibitors, and fluoroquinolones, which act against topoisomerases to inhibit DNA synthesis and replication, are usually highly effective against Mycoplasma pneumoniae and are the drugs of choice (25). However, only macrolides are recommended for children, as tetracycline and fluoroquinolone administration can lead to a number of age-related adverse events, such as cardiotoxicity and inhibition of bone growth $(42,43)$. Thus, in the present study azithromycin, a macrolide, was used to treat pediatric patients. However, approximately one third $(23 / 65)$ of patients did not respond to this treatment. Since the first report of macrolide resistance in 2001, it has increased rapidly, with the highest prevalence in East Asia $(44,45)$. The mechanism underlying macrolide resistance is related to point mutations in domain $\mathrm{V}$ of the $23 \mathrm{~S}$ ribosomal RNA gene of Mycoplasma pneumoniae and can usually be detected with the onset of the disease (46). CRP is the only factor demonstrated to significantly predict the efficacy of macrolides in MP patients (47). The results of the present study suggest that HGF may also be useful to assess the efficacy of azithromycin administration to MP patients. HGF has previously been used to evaluate the effectiveness of treatment in patients with acute brucellosis and acute myocardial infarction $(48,49)$. Though this suggests that HGF is a general indicator for inflammation or the immune response the results of the present study indicated that HRP had a higher sensitivity and specificity than CRP in assessing efficacy of azithromycin treatment of MP.

\section{Acknowledgements}

Not applicable.

\section{Funding}

The present study was funded by a grant from The Municipal Bureau of Health project (grant no. 2014KZ049).

\section{Availability of data and materials}

The datasets used and/or analyzed during the present study are available from the corresponding author on reasonable request.

\section{Authors' contributions}

LQL administered the medication, assessed clinical parameters and performed statistical analysis. ZHW collected patient samples, assessed clinical parameters and performed statistical analysis. HYY designed the study and drafted the manuscript. All authors read and approved the final manuscript.

\section{Ethics approval and consent to participate}

This study was approved by the Local Ethics Committee of Tianjin Nankai Hospital (approval no. 2017-018P), which waived written consent, as the study was observational and residual blood after completing the routine follow-up was used. Oral consent from each patient and their parent was obtained.

\section{Patient consent for publication}

Not applicable.

\section{Competing interests}

The authors declare that they have no competing interests.

\section{References}

1. Nakamura T, Nawa K and Ichihara A: Partial purification and characterization of hepatocyte growth factor from serum of hepatectomized rats. Biochem Biophys Res Commun 122: 1450-1459, 1984.

2. Tajima H, Matsumoto K and Nakamura T: Hepatocyte growth factor has potent anti-proliferative activity in various tumor cell lines. FEBS Lett 291: 229-232, 1991.

3. Panganiban RA and Day RM: Hepatocyte growth factor in lung repair and pulmonary fibrosis. Acta Pharmacol Sin 32: 12-20, 2011.

4. Ware LB and Matthay MA: Keratinocyte and hepatocyte growth factors in the lung: Roles in lung development, inflammation, and repair. Am J Physiol Lung Cell Mol Physiol 282: L924-L940, 2002.

5. Morimoto K, Amano H, Sonoda F, Baba M, Senba M, Yoshimine H, Yamamoto H, Ii T, Oishi K and Nagatake T: Alveolar macrophages that phagocytose apoptotic neutrophils produce hepatocyte growth factor during bacterial pneumonia in mice. Am J Respir Cell Mol Biol 24: 608-615, 2001. 
6. Nagahori T, Dohi M, Matsumoto K, Saitoh K, Honda ZI, Nakamura $T$ and Yamamoto K: Interferon- $\gamma$ upregulates the c-Met/hepatocyte growth factor receptor expression in alveolar epithelial cells. Am J Respir Cell Mol Biol 21: 490-497, 1999.

7. Matsumoto K, Okazaki H and Nakamura T: Novel function of prostaglandins as inducers of gene expression of HGF and putative mediators of tissue regeneration. J Biochem 117: 458-464, 1995.

8. Zarnegar R: Regulation of HGF and HGFR gene expression. EXS 74: 33-49, 1995

9. Matsuo R, Ohkohchi N, Murata S, Ikeda O, Nakano Y Watanabe M, Hisakura K, Myronovych A, Kubota T, Narimatsu H, et al: Platelets Strongly Induce Hepatocyte Proliferation with IGF-1 and HGF In Vitro. J Surg Res 145 279-286, 2008

10. Marchand-Adam S, Fabre A, Mailleux AA, Marchal J, Quesnel C, Kataoka H, Aubier M, Dehoux M, Soler P and Crestani B: Defect of pro-hepatocyte growth factor activation by fibroblasts in idiopathic pulmonary fibrosis. Am J Respir Crit Care Med 174: 58-66, 2006.

11. Grenier A, Chollet-Martin S, Crestani B, Delarche C, El Benna J, Boutten A, Andrieu V, Durand G, Gougerot-Pocidalo MA, Aubier M, et al: Presence of a mobilizable intracellular pool of hepatocyte growth factor in human polymorphonuclear neutrophils. Blood 99: 2997-3004, 2002.

12. Verghese GM, McCormick-Shannon K, Mason RJ and Matthay MA: Hepatocyte growth factor and keratinocyte growth factor in the pulmonary edema fluid of patients with acute lung injury. Biologic and clinical significance. Am J Respir Crit Care Med 158: 386-394, 1998

13. Yanagita K, Matsumoto K, Sekiguchi K, Ishibashi H, Niho Y and Nakamura T: Hepatocyte growth factor may act as a pulmotrophic factor on lung regeneration after acute lung injury. J Biol Chem 268: 21212-21217, 1993.

14. Yanagita K, Nagaike M, Ishibashi H, Niho Y, Matsumoto K and Nakamura T: Lung may have an endocrine function producing hepatocyte growth factor in response to injury of distal organs. Biochem Biophys Res Commun 182: 802-809, 1992.

15. Higa F, Akamine M, Furugen M, Hibiya K, Koide M, Tamayose M, Tamaki Y, Haranaga S, Arakaki N, Yara S, et al: Hepatocyte growth factor levels in Legionella pneumonia: A retrospective study. BMC Infect Dis 11: 74, 2011.

16. Yu H, Wang Y, Yu Q, Zhang H, Ma W, Shang S, Wang D: Significance of plasma hepatocyte growth factor in diagnosis of benign and malignant solitary pulmonary nodules. Int J Clin Exp Pathol 8: 2063-2067, 2015.

17. Abednazari H, Xu J, Millinger E, Brudin L, Forsberg P and Nayeri F: Hepatocyte growth factor is a better indicator of therapeutic response than C-reactive protein within the first day of treatment in pneumonia. Chemotherapy 52: 260-263, 2006.

18. Atkinson TP, Balish MF and Waites KB: Epidemiology, clinical manifestations, pathogenesis and laboratory detection of Mycoplasma pneumoniae infections. FEMS Microbiol Rev 32 956-973, 2008

19. Bajantri B, Venkatram S and Diaz-Fuentes G: Mycoplasma pneumoniae: A potentially severe infection. J Clin Med Res 10 535-544, 2018.

20. Decaux G, Szyper M, Ectors M, Cornil A and Franken L: Central nervous system complications of Mycoplasma pneumoniae. J Neurol Neurosurg Psychiatry 43: 883-887, 1980.

21. Squadrini F, Lami G, Pellegrino F, Pinelli G, Bavieri M, Fontana A and Bisetti A: Acute hepatitis complicating Mycoplasma pneumoniae infection. J Infect 16: 201-202, 1988.

22. Gdalevich M, Haas EJ, Dukhan L, Katz M, Zelenski V, Moran-Gilad J: Control of a Mycoplasma pneumoniae outbreak in an institutional setting using azithromycin prophylaxis. Front Public Health 5: 366, 2017

23. Nilsson AC, Björkman P and Persson K: Polymerase chain reaction is superior to serology for the diagnosis of acute Mycoplasma pneumoniae infection and reveals a high rate of persistent infection. BMC Microbiol 8: 93, 2008

24. Zhang L, Zong ZY, Liu YB, Ye H and Lv XJ: PCR versus serology for diagnosing Mycoplasma pneumoniae infection: A systematic review \& meta-analysis. Indian J Med Res 134: 270-280, 2011.

25. Lee H, Yun KW, Lee HJ and Choi EH: Antimicrobial therapy of macrolide-resistant Mycoplasma pneumoniae pneumonia in children. Expert Rev Anti Infect Ther 16: 23-34, 2018

26. Bénet T, Picot VS, Awasthi S, Pandey N, Bavdekar A, Kawade A, Robinson A, Rakoto-Andrianarivelo M, Sylla M, Diallo S, et al; For The Gabriel Network: Severity of Pneumonia in Under 5-Year-Old Children from Developing Countries: A Multicenter, Prospective, Observational Study. Am J Trop Med Hyg 97: 68-76, 2017.
27. Tablan OC and Reyes MP: Chronic interstitial pulmonary fibrosis following Mycoplasma pneumoniae pneumonia. Am J Med 79: 268-270, 1985

28. Korppi M, Heiskanen-Kosma T and Kleemola M: Incidence of community-acquired pneumonia in children caused by Mycoplasma pneumoniae: Serological results of a prospective, population-based study in primary health care. Respirology 9: 109-114, 2004

29. Lee WJ, Huang EY, Tsai CM, Kuo KC, Huang YC, Hsieh KS, Niu CK, Yu HR: Role of serum Mycoplasma pneumoniae IgA, $\mathrm{IgM}$, and $\mathrm{IgG}$ in the diagnosis of Mycoplasma pneumoniae-related pneumonia in school-age children and adolescents. Clin Vaccine Immunol 24: e00471-16, 2017.

30. Chinese Medial Association pediatric branch respiratory group. Editor Committee of Chinese Journal of Pediatrics: Management guidance of community acquired pneumonia. Chinese Journal of Pediatrics 51: 745-752, 856-862, 2013.

31. Joyce SM: Sputum analysis and culture. Ann Emerg Med 15: 325-328, 1986

32. Kazachkov MY, Hu PC, Carson JL, Murphy PC, Henderson FW and Noah TL: Release of cytokines by human nasal epithelial cells and peripheral blood mononuclear cells infected with Mycoplasma pneumoniae. Exp Biol Med (Maywood) 227: 330-335, 2002

33. Ito Y, Correll K, Zemans RL, Leslie CC, Murphy RC and Mason RJ: Influenza induces IL-8 and GM-CSF secretion by human alveolar epithelial cells through $\mathrm{HGF} / \mathrm{c}-\mathrm{Met}$ and TGF- $\alpha /$ EGFR signaling. Am J Physiol Lung Cell Mol Physiol 308: L1178-L1188, 2015.

34. Guo J, Huang F, Liu J, Chen Y, Wang W, Cao B, Zou Z, Liu S, Pan J, Bao C, et al: The Serum Profile of Hypercytokinemia Factors Identified in H7N9-Infected Patients can Predict Fatal Outcomes. Sci Rep 5: 10942, 2015.

35. Lu A, Wang C, Zhang X, Wang L and Qian L: Lactate Dehydrogenase as a Biomarker for Prediction of Refractory Mycoplasma pneumoniae Pneumonia in Children. Respir Care 60: 1469-1475, 2015.

36. Wang M, Wang Y, Yan Y, Zhu C, Huang L, Shao X, Xu J, Zhu H, Sun X, Ji W, et al: Clinical and laboratory profiles of refractory Mycoplasma pneumoniae pneumonia in children. Int J Infect Dis 29: 18-23, 2014

37. Scott JA, Wonodi C, Moïsi JC, Deloria-Knoll M, DeLuca AN, Karron RA, Bhat N, Murdoch DR, Crawley J, Levine OS, et al; Pneumonia Methods Working Group: The definition of pneumonia, the assessment of severity, and clinical standardization in the Pneumonia Etiology Research for Child Health study. Clin Infect Dis 54 (Suppl 2): S109-S116, 2012.

38. Pépin J, Demers AM, Mberyo-Yaah F, Jaffar S, Blais C, Somsé P, Bobossi G and Morency P: Acute lower respiratory infections among children hospitalized in Bangui, Central African Republic: Toward a new case-management algorithm. Trans $\mathrm{R}$ Soc Trop Med Hyg 95: 410-417, 2001.

39. Sehgal V, Sethi GR, Sachdev HP and Satyanarayana L: Predictors of mortality in subjects hospitalized with acute lower respiratory tract infections. Indian Pediatr 34: 213-219, 1997.

40. Garau J: Role of beta-lactam agents in the treatment of community-acquired pneumonia. Eur J Clin Microbiol Infect Dis 24: 83-99, 2005.

41. Huong PL, Thi NT, Nguyet NT, Van TK, Hang DT, Huong VT, Anh DD and Sasaki T: First report on clinical features of Mycoplasma pneumoniae infections in Vietnamese children. Jpn J Infect Dis 60: 370-373, 2007.

42. Guo D, Cai Y, Chai D, Liang B, Bai N and Wang R: The cardiotoxicity of macrolides: A systematic review. Pharmazie 65: 631-640, 2010

43. Demers P, Fraser D, Goldbloom RB, Haworth JC, LaRochelle J, MacLean R and Murray TK: Effects of tetracyclines on skeletal growth and dentition. A report by the Nutrition Committee of the Canadian Paediatric Society. Can Med Assoc J 99: 849-854, 1968.

44. Okazaki N, Narita M, Yamada S, Izumikawa K, Umetsu M, Kenri T, Sasaki Y, Arakawa Y and Sasaki T: Characteristics of macrolide-resistant Mycoplasma pneumoniae strains isolated from patients and induced with erythromycin in vitro. Microbiol Immunol 45: 617-620, 2001.

45. Liu Y, Ye X, Zhang H, Xu X, Li W, Zhu D and Wang M: Antimicrobial susceptibility of Mycoplasma pneumoniae isolates and molecular analysis of macrolide-resistant strains from Shanghai, China. Antimicrob Agents Chemother 53: 2160-2162, 2009 . 
46. Cao B, Zhao CJ, Yin YD, Zhao F, Song SF, Bai L, Zhang JZ Liu YM, Zhang YY, Wang H, et al: High prevalence of macrolide resistance in Mycoplasma pneumoniae isolates from adult and adolescent patients with respiratory tract infection in China. Clin Infect Dis 51: 189-194, 2010.

47. Seo YH, Kim JS, Seo SC, Seo WH, Yoo Y, Song DJ and Choung JT: Predictive value of $\mathrm{C}$-reactive protein in response to macrolides in children with macrolide-resistant Mycoplasma pneumoniae pneumonia. Korean J Pediatr 57: 186-192, 2014.
48. Ozden M, Kalkan A, Demirdag K, Kilic SS, Denk A and Yuce P: Hepatocyte growth factor (HGF) in patients with acute brucellosis. Scand J Infect Dis 36: 109-113, 2004.

49. Soeki T, Tamura Y, Shinohara H, Tanaka H, Bando K and Fukuda N: Serial changes in serum VEGF and HGF in patients with acute myocardial infarction. Cardiology 93: 168-174, 2000. 